\title{
The attention-aversion gap: how allocation of attention relates to loss aversion
}

\author{
Tomás Lejarraga $^{\mathrm{a}, \mathrm{c}, *}$, Michael Schulte-Mecklenbeck ${ }^{\mathrm{b}, \mathrm{c}}$, Thorsten Pachur ${ }^{\mathrm{c}}$, Ralph Hertwig ${ }^{\mathrm{c}}$ \\ ${ }^{a}$ Universitat de les Illes Balears, Carretera de Valldemossa, $\mathrm{km}$ 7,5, 07122 Palma, Spain \\ ${ }^{\mathrm{b}}$ Universität Bern, Engehaldenstrasse 4, 3012 Bern, Switzerland \\ ${ }^{\mathrm{c}}$ Max Planck Institute for Human Development, Lentzeallee 94, 14195 Berlin, Germany
}

\section{A R T I C L E I N F O}

\section{Keywords:}

Loss attention

Loss aversion

MouselabWEB

process tracing

\begin{abstract}
A B S T R A C T
Loss aversion is often assumed to be a basic and far-reaching psychological regularity in behavior. Yet empirical evidence is accumulating to challenge the assumption of widespread loss aversion in choice. We suggest that a key reason for the apparently elusive nature of loss aversion may be that its manifestation in choice is state-dependent and distinct from a more state-independent principle of heightened attention to losses relative to gains. Using data from process-tracing studies, we show that people invest more attentional resources when evaluating losses than when evaluating gains, even when their choices do not reflect loss aversion. Our evidence converges with previous findings on how losses influence exploratory search as well as physiological, hormonal, and neural responses. Increased attention to losses relative to gains seems to be a necessary but not a sufficient condition for loss aversion in choice.
\end{abstract}

\section{Introduction}

Loss aversion-the tendency to weight losses more heavily than equivalent gains-has been described as "one of the basic phenomena of choice under both risk and uncertainty" (Tversky \& Kahneman, 1992, p. 298, emphasis added]. ${ }^{1}$ The idea that "losses loom larger than gains" (Kahneman \& Tversky, 1979) when people make decisions-that the pain of losing is much more significant than the pleasure of gainin$\mathrm{g}$-has been central to the understanding of how people make decisions under risk (and beyond; Tversky \& Kahneman, 1991). It has had a profound impact in psychology, economics, and finance, and has also influenced fields such as political science and law. Loss aversion has been invoked to explain a variety of empirical phenomena, including the endowment effect (Kahneman, Knetsch, \& Thaler, 1990; Thaler, 1980), the disposition effect (Weber \& Camerer, 1998), effort in sports (Riedl, Heuer, \& Strauss, 2015), and underinvestment in the stock market (Benartzi \& Thaler, 1995).

Loss aversion was initially demonstrated in decisions under risk, where people select between options whose possible outcomes and corresponding probabilities are known. For example, someone whose preferences are described by the original parameters of prospect theory (Tversky \& Kahneman, 1992) would reject a gamble that offers a $50 \%$ chance to win $\$ 1000$ and a $50 \%$ chance to lose $\$ 1000$, because the potential loss of $\$ 1000$ outweighs the possible gain of the same size. Although both options - the gamble and the safe option of staying with $\$ 0$ - have the same expected value, this overweighting of losses renders the gamble relatively unattractive. ${ }^{2}$ To be attractive, a gamble with a $50 \%$ chance of losing $\$ 1000$ would need to offer a possible gain (again with a 50\% chance) of roughly $\$ 2750$ (Tversky \& Kahneman, 1992). Loss aversion has been viewed as "one of the most fundamental and well-documented biases" (Rozin \& Royzman, 2001, p. 306).

Although the concept of loss aversion appears to be well established, there is also evidence challenging its generalized nature. Ert and Erev (2013) were among the first to note the empirical inconsistency of findings on loss aversion in decisions under risk. Specifically, they identified a set of situations in which loss aversion is unlikely to emerge, including situations with feedback and situations with a clear and safe status quo. ${ }^{3}$ Moreover, Walasek and Stewart (2015) showed

\footnotetext{
* Corresponding author.

E-mail addresses: tomas.lejarraga@uib.eu (T. Lejarraga), research@schulte-mecklenbeck.com (M. Schulte-Mecklenbeck), pachur@mpib-berlin.mpg.de (T. Pachur), hertwig@mpib-berlin.mpg.de (R. Hertwig).

${ }^{1}$ Decisions under risk are those where the decision maker knows all possible outcomes and their corresponding probabilities. Decisions under uncertainty are those where the decision maker lacks information about the decision problem, such as the possible outcomes or their probabilities.

2 This is independent of risk attitude, as modeled by the curvature of the value function.

${ }^{3}$ An absence of loss aversion had previously been observed in riskless choice (Gal, 2006; Morewedge, Shu, Gilbert, \& Wilson, 2009; Novemsky \& Kahneman, 2005; Ritov \& Baron, 1992).
} 
that loss aversion can be made to appear, disappear, and even reverse by manipulating the ranges of possible outcomes that people could expect to obtain. As predicted by decisions-by-sampling theory (Walasek \& Stewart, 2015), they showed that loss aversion emerged in a context where gains ranged between $\$ 0$ and $\$ 40$ and losses between $\$ 0$ and $\$ 20$, but disappeared when gains and losses both ranged between $\$ 0$ and $\$ 20$. According to decisions-by-sampling theory, it is the asymmetry in the magnitudes of the possible gains and losses (specifically, that the former are usually larger than the latter) that leads to the occurrence of loss aversion.

Systematic reviews and comprehensive analyses have confirmed the empirical fragility of loss aversion. Studies using large and diverse sets of choice problems have found only small, though reliable, degrees of loss aversion (Glöckner \& Pachur, 2012; Kellen, Pachur, \& Hertwig, 2016; Pachur, Mata, \& Hertwig, 2017). Yechiam and Hochman (2013b) reviewed articles that examined loss aversion using symmetric gambles (i.e., gambles offering an equal chance of winning or losing an equal number of points or amount of money), and found that only four out of 24 studies reported evidence for loss-averse choices when averaged across participants. The four studies in which there was evidence for loss aversion used decisions from description, as did the original studies of Tversky and Kahneman (1992). In decisions from description (also known as decisions under risk), decision makers are informed about all possible outcomes of the options and their corresponding probabilities. In decisions from experience, in contrast, they learn about the outcomes and their probabilities from previous decisions or by sampling options (Hertwig, Barron, Weber, \& Erev, 2004; Hertwig \& Erev, 2009). In the review conducted by Yechiam and Hochman (2013b), none of the 13 studies examining decisions from experience found evidence for loss aversion. As evidence against loss aversion accumulated, Yechiam (2018) went back to the early studies of loss aversion (Fishburn \& Kochenberger, 1979; Galanter \& Pliner, 1974) that Kahneman and Tversky (1979) had drawn on to substantiate the assumption of loss aversion as a stylized fact in their formulation of prospect theory. Yechiam concluded that this early evidence had been "over-interpreted" (p. 1) by Kahneman and Tversky.

A recent review by Gal and Rucker (2018b) went even further. These authors questioned the evidence for loss aversion on conceptual grounds, attributing the idea that it is a ubiquitous regularity in human choice to its intuitive appeal among behavioral scientists. This led to the existence of loss aversion being overgeneralized-often inappropriately-to everyday situations. Gal and colleagues did not mince their words in concluding that loss aversion, "the most important idea in behavioral decision-making," is "a fallacy" (Gal, 2018) and suggested "moving beyond loss aversion as a generalized principle" (Gal \& Rucker, 2018b, p. 513). Irrespective of whether loss aversion is indeed the most important idea in behavioral decision-making research, the key unresolved issue is this: Why is it that the empirical phenomenon of loss aversion is so fragile and even elusive? In search of an answer, let us first turn to the conceptual question of what can reasonably be considered as a manifestation of loss aversion.

\section{What is loss aversion-and what is it not?}

Although Edgeworth observed that "minus pain is sweeter than plus pleasure" as early as 1877 (Edgeworth, 1877, p. 75), Kahneman and Tversky (1979) were the first to test this notion empirically and to give it a name: loss aversion. Their empirical test required people to make choices between gambles. Accordingly, prospect theory's concept of loss aversion has long been closely aligned with choice behavior. In fact, Tversky and Kahneman (1992) described loss aversion as one of the "basic phenomena of choice" (p. 298). Its relationship to other psychological dimensions came to the fore when neuroscientists began to track neural responses in risky choices and observed an asymmetric neural activation pattern in response to gains and losses that, in turn, was correlated with estimates of loss aversion in choices (Canessa et al.,
2013; Sokol-Hessner, Camerer, \& Phelps, 2012; Tom, Fox, Trepel, \& Poldrack, 2007). These neurological observations were interpreted as signatures of loss aversion, and the label neural loss aversion was introduced. This interpretation, however, raises a number of questions: How many types of loss aversion are there? Is there a "neural" type, a "choice" type, an "attentional" type, an "emotional" type, a "search" type, and so on? And, if so, are they isomorphic expressions of the same core concept?

There is an alternative to the notion that neural and other dimensions of loss aversion are all constitutive of loss aversion. In fact, Yechiam and Hochman adopted a different interpretation. They viewed the observed regularity that the prospect of a loss increases attention more than the prospect of an equal gain as distinct from loss aversion. Because prospect theory, the framework within which loss aversion was conceptualized, is mute about attentional processes, they named the observed regularity loss attention (Yechiam \& Hochman, 2013a, 2014) rather than attentional loss aversion. So what exactly is loss aversion and, by extension, what counts as evidence for it?

To appreciate this conceptual challenge, let us take a closer look at these two interpretations of loss aversion. One sees it as a phenomenon in people's choices. Indeed, its mathematical definition in cumulative prospect theory (Tversky \& Kahneman, 1992) and its measurement in terms of the $\lambda$ parameter (see Section 7.2 for details) firmly situate loss aversion in the domain of valuation and choice between gambles with numerical outcomes-and thus in the influential tradition of the revealed preference approach in economics. This approach assumes that people only reveal what they truly prefer through observable decisions with real consequences (Samuelson, 1938). From this perspective, it is necessary to study preferences (including loss aversion) on the basis of overt and incentivized behaviors. The advantage of this interpretation is that it permits researchers to make precise behavioral predictions and test them empirically. Patterns of neural activation, attention, and search may or may not align with loss aversion in choice, but they cannot be used to test the reality of loss aversion. The evidence that counts is human choice. It seems that Yechiam and Hochman's (2013a) conclusion that loss aversion is fragile and elusive is premised on this interpretation of the construct.

Another interpretation of loss aversion assumes it to be a latent psychological construct (such as intelligence or the Big Five dimensions of personality) that can be inferred from various indicators. Therefore, loss aversion can also manifest in neurophysiological and cognitive processes, such as asymmetric responses of the autonomic nervous system (Sokol-Hessner et al., 2009; Yechiam, Retzer, Telpaz, \& Hochman, 2015), heart rate (Hochman \& Yechiam, 2011), exploratory search (Lejarraga \& Hertwig, 2017; Lejarraga, Hertwig, \& Gonzalez, 2012; Yechiam, Zahavi, \& Arditi, 2015), hormonal response (Burke et al., 2018; Margittai et al., 2018), neural response (Canessa et al., 2013; Sokol-Hessner et al., 2012; Tom et al., 2007), attention (Yechiam \& Hochman, 2013b) and, ultimately, choice (Tversky \& Kahneman, 1992). According to this interpretation, evidence of these different processes count as evidence of loss aversion, as, for instance, in Tom et al. (2007). One potential weakness of this interpretation is that it risks broadening the definition of loss aversion to such a degree that "phenomena that have nothing to do with loss aversion have nonetheless been interpreted to reflect loss aversion" (Gal, 2018). To illustrate, loss aversion has been conjectured to be the cause of the status quo bias (Samuelson \& Zeckhauser, 1988), which is the tendency to prefer to avoid change and retain the status quo. The underlying logic is that the loss of the status quo weighs more heavily than the potential gain of a change (Kahneman, Knetsch, \& Thaler, 1991). However, the status quo bias could also result from a preference for inaction over action (Gal \& Rucker, 2018a) or simply from inertia or effort avoidance (Yechiam, 2018). Similarly, loss aversion has also been assumed to underlie the endowment effect (e.g., Kahneman, Knetsch, \& Thaler, 1990) - the phenomenon that sellers value a given object more highly than buyers-but other mechanisms, such as response bias or 
probability weighting, are conceivable (Pachur \& Scheibehenne, 2017). Importantly, the assumption that loss aversion manifests across multiple psychological dimensions raises the conceptual problem of how these manifestations are related.

We are not aware of any conceptual guide (in prospect theory or elsewhere) that would help to understand and predict how, for example, visual attention to losses relates to the subsequent weighting of those losses in choice situations (see Pachur, Schulte-Mecklenbeck, Murphy, \& Hertwig, 2018). The implicit assumption in the interpretation of loss aversion as a latent construct appears to be that loss aversion encompasses affective, cognitive, and neural processes that precede and accompany choice. This, in turn, means that when loss aversion occurs in choice, it will also have occurred in the preceding or accompanying information processing - and, vice versa, when there are signals of loss aversion in those processes, choice will display loss aversion as well. In other words, indicators of information processing and choice are synchronized such that loss aversion in one translates into loss aversion in the other.

There is, however, a third interpretation of loss aversion-one that we will entertain here. On the one hand, we would find it implausible to divorce loss aversion in choice from its preceding and accompanying processes on other dimensions. However, it is not mandatory to assume that all other processes are subject to what happens in choice. If a person pays more attention to or invests more search effort in exploring the prospect of a loss relative to the prospect of a gain, why should they necessarily be constrained to show this "bias" in choice as well? If this were the case, it would rob choice behavior of any autonomy and agency; rather, choices would be determined by the preceding processes. This strikes us as implausible. Instead, we suggest that what is required is a better empirical and theoretical understanding of how loss aversion in choice relates to the dynamics of the other processes. Specifically, we propose that loss aversion-as manifest in choice-is not a general and context-invariant psychological regularity; instead, it may be a state-dependent tendency in people's choices, one that is informed but not determined by attentional processes. This view builds on two proposals of how loss aversion can be placed within the dynamics of evolution.

First, several researchers have argued that losses are generally more significant than gains. For example, the loss of energy has a greater impact on an organism's fitness than does an equivalent gain of energy. A loss may kill the organism if certain needs are no longer met, whereas a gain "merely" increases its chances of survival and its lifespan (Aktipis \& Kurzban, 2005; McDermott, Fowler, \& Smirnov, 2008; Mishra, Barclay, \& Sparks, 2017). This implies that natural selection could have given rise to an optimal forager who exhibits loss aversion in choice behavior (for a critique of this view, see Houston, Fawcett, Mallpress, \& McNamara, 2014). Rozin and Royzman (2001) extended the argument beyond foraging, as did Baumeister, Bratslavsky, Finkenauer, and Vohs (2001): "Survival requires urgent attention to possible bad outcomes, but it is less urgent with regard to good ones. Hence, it would be adaptive to be psychologically designed to respond to bad more strongly than good" (p. 325). Given the asymmetric fitness consequences of equivalent gains and losses, "organisms should be designed to be more concerned with avoiding losses than with realizing gains" (Aktipis \& Kurzban, 2005, p. 143). Haselton and Buss (2000) developed these ideas further in their error-management theory. They proposed that perceptual and cognitive biases could be caused by the error structure that people face. Because some errors are more costly than others, organisms should have evolved perceptual and cognitive biases that make them less likely to commit costly errors. For example, women tend to underperceive men's commitment because the cost of falsely inferring a mate's commitment when none exists is greater than the cost of failing to infer commitment when it does exist (Haselton \& Buss, 2000). Error management has been observed in a variety of behavioral domains and has been suggested to be "a general feature of life" (Johnson, Blumstein, Fowler, \& Haselton, 2013, p. 474).
This general state- and context-independent concern for losses contrasts with a second view, according to which an organism's risk preference depends on its need state. This is the assumption underlying risk-sensitivity theory, which models the problem of "optimally" foraging from stochastic food sources (Stephens, 1981; Stephens \& Krebs, 1986). The key concept is the need state. Needs refer to the distance between the organism's current state and its goal (Barclay, Mishra, \& Sparks, 2018; Mishra, Gregson, \& Lalumiere, 2012). In high-need states, an organism should prefer a risky option if it is the only available option that can possibly meet its needs, even if it involves the possibility of a loss. In low-need states, the same organism should prefer a safer option that can meet its needs without entailing the risk of a possible loss. At any need state, if two available options are sufficient to meet the organism's needs, and the variance of those options does not entail the possibility of the needs not being met, the organism will choose the option with the higher expected value. This preference holds even when the riskier option offers a lower expected value. To illustrate, someone needing $\$ 10,000$ for an urgent heart transplant is likely to prefer a $10 \%$ chance of getting $\$ 10,000$ to the certainty of getting $\$ 2000$, even though the safe option's expected value is twice as large. Mallpress, Fawcett, Houston, and McNamara (2015) incorporated these ideas into an evolutionary model where a forager needs energy to build up reserves for reproduction and prevent starvation. They observed that the pattern of choice implied by prospect theory-including loss aversion-may have been adaptive in an environment in which options vary stochastically and are autocorrelated in time.

Our central thesis is inspired by both of these evolutionary lines of reasoning. Numerous researchers have argued that it seems adaptive for humans to have evolved a predisposition to be attentive to the threat of a loss and less so to the promise of a gain. A gain is good, but a loss may be deadly. Given this invariable loss-gain asymmetry, it may be adaptive to devote more of the limited processing capacity to exploring the threat of losses than the promise of gains. This does not mean that people invariably overweight losses relative to gains when making choices. In some circumstances, the utility of unlikely but substantial gains may trump the negative value of substantial losses. As such, attention to losses does not automatically imply loss-averse behavior; information taken in through attention mechanisms informs behavior, but it does not determine choice. Specifically, we suggest that heightened attention to losses relative to gains could be a widespread principle in cognitive dimensions such as visual attention and search, as well as in neural and hormonal dimensions. In contrast, loss aversion-a behavioral response to the threat of losses-may or may not occur, depending on the organism's state (e.g., can the organism afford to forego potential gains?). In other words, loss aversion, if it occurs, is likely to be preceded by signals of loss attention; however, loss attention is not sufficient to produce loss aversion. This interpretation would help to explain the empirical inconsistencies surrounding loss aversion in the experimental literature, and to reconcile contrasting claims from evolutionary theorists who have proposed both a state-independent asymmetry in the concern for losses and state-dependent loss aversion.

With this third interpretation of loss aversion in mind, we next turn to the relationship between loss attention and loss aversion, aiming to cast further light on why loss aversion is not always observed. From this point on, we adopt Yechiam and Hochman's (2013a) distinction between loss aversion and loss attention. Using two distinct concepts gives us more degrees of freedom to describe the nondeterministic relationship between choice and processes of attention and search.

\section{Current evidence on the relationship of loss attention and loss aversion}

Two recent empirical studies have examined the relationship between attention and aversion to losses. Pachur et al. (2018) tested whether attention patterns in decisions between gambles reflect the psychological constructs assumed in prospect theory, such as nonlinear 
probability weighting, risk aversion, and loss aversion. The authors had participants choose between gambles, and then estimated each participant's prospect theory parameters from those choices. One of these parameters is $\lambda$, the loss-aversion parameter. They also examined participants' individual attention patterns using MouselabWeb, a computer program that records the sequences and lengths of information intake. The authors examined the correlation between participants' prospect theory parameters and their measures of attention, and found that loss aversion (as measured by $\lambda$ ) was associated with relative attention to losses versus gains in mixed gambles. In a subsequent experiment, they manipulated participants' attention to losses or gains, causing systematic differences in their choices, which were then reflected in prospect theory parameters. In particular, they found that exposing people to losses for longer than to gains increased subsequent loss aversion in choice, as captured by $\lambda$. This result indicates that attention allocation can to some extent cause choice regularities that are captured by prospect theory (Pachur et al., 2018).

In a related study, Ashby, Yechiam, and Ben-Eliezer (2018) found somewhat different results. Like Pachur et al. (2018), the authors examined the relationship between relative attention to losses and choice, but also between relative attention and valuation. In the valuation task, participants were asked to indicate how much gambles were worth to them, but did not make choices among them. The authors estimated participants' individual $\lambda$ from their choices between gambles, and also from their valuations of those gambles. The individual patterns of attention were recorded using eye tracking. In three studies, they found evidence that attention to losses was not related to how individuals weighted losses relative to gains. In other words, loss attention and loss aversion were not related in people's choices. However, they did find a relationship between loss attention and their measure of loss aversion as estimated from people's valuation of the gambles.

These contrasting results demonstrate that the relationship between loss attention and loss aversion is, as yet, far from settled. In the next section, we specify three unresolved issues.

\section{Three unresolved issues}

First, as outlined above, loss aversion has sometimes been conceptualized as a multidimensional construct, which can manifest across various neurophysiological and cognitive processes (including hormones and neural activation). Implicit in this view is the assumption that these various manifestations of loss aversion operate in tandem, such that, for example, neural signatures and hormonal markers necessarily correlate with the degree of loss aversion in choice (because they reflect a common biological phenomenon). In contrast, a revealedpreference conceptualization of loss aversion restricts loss aversion to choice, and, by definition, implies that phenomena such as heightened physiological responses to losses (e.g., pupil dilation, heart rate, and search) are strictly distinct from loss aversion.

The second issue is also conceptual. Psychologists and evolutionary theorists who have attempted to rationalize loss aversion in the context of evolutionary dynamics have made two conflicting claims. Some scholars have argued that, because losses have a higher impact on fitness than gains, organisms should be designed to be generally more concerned with losses than with gains. Others have questioned this notion of a generalized adaptation and argued that the tendency to choose in a loss-averse manner may depend on the organism's current need state.

The third issue concerns the mixed experimental evidence on the relationship between attention and aversion to losses. Pachur et al. (2018) found a moderate but robust correlation between a measure of relative attention to losses and a measure of loss aversion in choices. They provided evidence that attention and aversion to losses do relate. In contrast, Ashby et al. (2018) conducted three experiments similar to those of Pachur et al. (2018)—but measuring attention by means of eye tracking-and found no correlation between loss attention and a measure of loss aversion in choices. However, using an alternative measure of loss aversion, derived from valuation instead of choice, Ashby et al. (2018) did find a correlation with attention.

With this study, we contribute to addressing these three issues and propose a new conceptualization of the relationship between attention and aversion to losses. Specifically, we argue that heightened attention to losses relative to gains is a more general phenomenon than is loss aversion displayed in choice, and we present empirical evidence supporting the predictions following from our conceptualization. Our empirical analyses focus on two questions: First, do losses promote more attention than gains? Second, assuming we find such loss attention, how does it relate to the degree of loss aversion in choice? If, as we argue, increased attention to losses is a general phenomenon that informs choice but does not determine it, one would expect to often find a lack of loss aversion even in the presence of loss attention. The reverse pattern, loss aversion in the absence of loss attention, should, by contrast, be rare. We conclude by discussing the implications of our findings for the conceptualization of loss aversion.

\section{Choices between gambles: the limits of a convenient paradigm}

Experimental tasks involving choices between gambles are archetypal in the study of risky choice, and are the home turf of prospect theory (Kahneman \& Tversky, 1979). For example, a participant is given a choice between two options: a sure gain of EUR 3 and a gamble offering an $80 \%$ chance of winning EUR 4 and a $20 \%$ chance of winning nothing. Participants make several decisions of this type, with varying outcomes, probabilities, and the possibility of winning or losing money. A common way to measure loss aversion in such a task is by fitting the parameters of prospect theory (which disentangle the contribution of probability weighting, risk aversion, and loss aversion) to observed choices and assessing the estimated parameter that reflects how losses are weighted (with $\lambda>1$ indicating loss aversion; see the formal specification of prospect theory in the Appendix A).

This paradigm is convenient because researchers can make choice problems vary in meaningful and systematic ways and assess how decision makers respond to manipulations in the stimuli. However, researchers using this paradigm are limited to observing choice, with no opportunity to inspect dimensions of behavior that could reveal aspects of information processing. For example, how people proceed sequentially through information and how they allocate attention are two measures that could reveal people's attention to losses. Fortunately, methodological tools do exist that provide insights into how people process information in decisions.

\subsection{Mouselab: a window onto the cognitive underpinnings of choice}

The Mouselab method is one such tool (Payne, Bettman, \& Johnson, 1988). Mouselab is a process-tracing tool that allows researchers to monitor the information acquisition process of decision makers. Other tools used for this purpose are eye-trackers and mouse-tracking (Schulte-Mecklenbeck et al., 2017). In Mouselab studies, relevant information is hidden behind boxes, and the decision maker uses the mouse cursor to open these boxes, revealing the information hidden behind. Fig. 1 shows a sample decision problem. The top row of boxes represents one option: a gamble. The box labeled "Outcome A1" contains one possible outcome of the gamble; the box labeled "Probability A1," its corresponding probability. The other possible outcome and its probability are hidden behind the boxes "Outcome A2" and "Probability A2," respectively. The bottom row displays the other option, with an equivalent structure but different values behind the boxes. Mouselab keeps track of how participants open these boxes to learn about the choice problem, giving researchers access to indicators of attention and decision processes, such as the frequency and order of information search. We used box opening time as a measure of attention paid to losses and gains. 


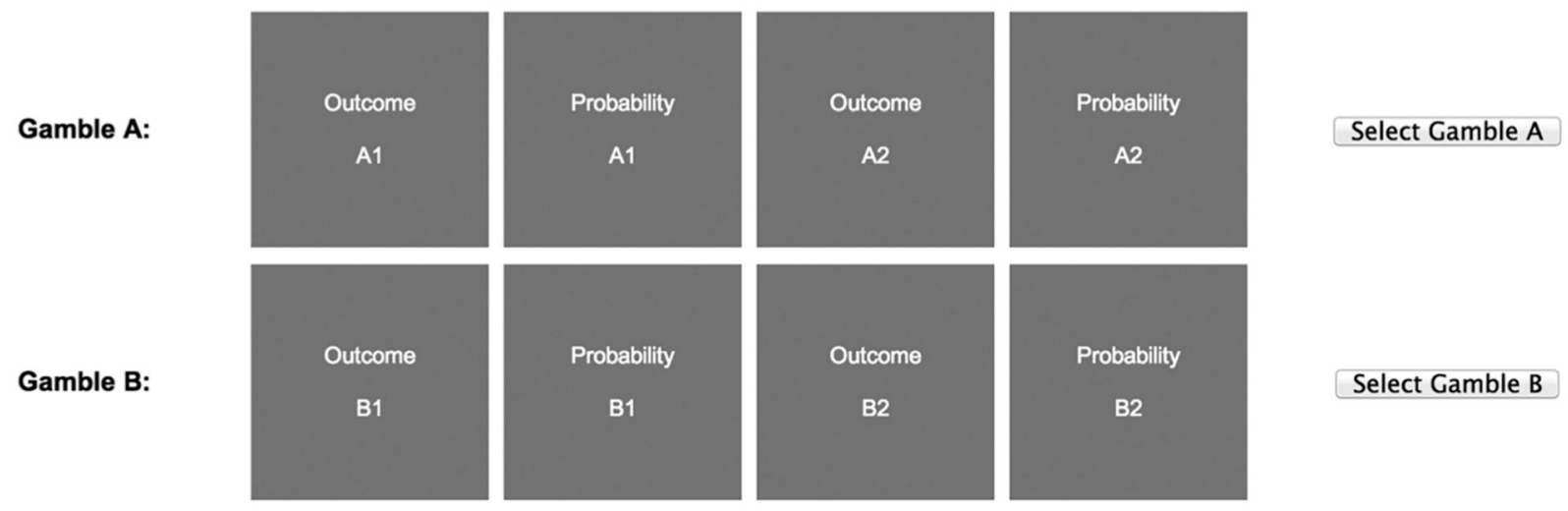

Fig. 1. MouselabWeb: Horizontal display of a decision problem. The problem involves a choice between Gamble A and Gamble B. Each gamble offers two possible outcomes, each with corresponding probabilities. The original labels were in German.

\section{Method}

\subsection{Are people more attentive to losses than to gains?}

We analyzed data from two experiments studying decisions under risk between gambles in a description-based setup. Both experiments used MouselabWEB (Willemsen \& Johnson, 2019)—a browser-based version of Mouselab-in a repeated-measures design. The only difference between the two experiments was that different acquisition modes were used: mouseover and click. In mouseover mode, the person moves the mouse pointer over the box on the screen and the box opens automatically to reveal the information hidden behind; no clicking is necessary. As long as the cursor hovers over the box, the information is displayed. As soon as the cursor leaves the box, the information disappears. In the click mode, the participant has to click on a box to reveal the information. Again, the information is shown as long as the mouse cursor hovers over the box and the mouse is clicked, and the box closes automatically once the mouse is no longer clicked. MouselabWEB records the number of box openings, the duration of each box opening, and the order in which boxes are opened.

\subsection{Datasets}

We used the data collected for Experiment 1 in Pachur et al. (2018) in combination with unpublished data from a similar experiment that was conducted to examine the difference between the two acquisition modes (Schulte-Mecklenbeck, Pachur, Murphy, \& Hertwig, 2014). ${ }^{4}$ Both experiments were conducted at the Max Planck Institute for Human Development, Berlin. Participants were recruited through adverts in newspapers and at universities. The sample consisted primarily of university students and university-educated adults, but also the wider public. Ninety people (48 female, $M=26.1$ years, $S D=9.1$ years) participated in the Pachur et al. (2018) experiment and 91 people (53 female, $M=25.3$ years, $S D=6.7$ years) in the second experiment. We merged the two datasets for the purpose of the present analysis. At the start of each session, participants were given a EUR 10 endowment. They were informed that they would have to make a series of choices between two gambles, and that their choices would determine a performance-contingent payment. Gains were added to the initial endowment and losses subtracted from it. Therefore, each participant was compensated with the fixed payment of EUR 10 plus or minus a performance-contingent payment that ranged from EUR -9.1 to EUR 9.8 ( $M=1.3, S D=4.8)$ in the Pachur et al. (2018) experiment, and from EUR -9.8 to EUR $9.8(M=2.4, S D=4.9)$ in the second experiment.

\footnotetext{
${ }^{4}$ The conclusions drawn in the present work hold across both acquisition modes; see Appendix. Data and analysis code for both experiments are available at https://github.com/michaelschulte/AttentionAversionGap
}

In both experiments, each participant encountered the 91 choice problems twice, once in each of two experimental sessions that were conducted 3 weeks apart. The problems were presented in a different random order each time. Within each session, half of the problems were presented in a horizontal setup (as shown in Fig. 1) and the other half in a vertical setup. Problems presented in a horizontal setup in the first trial were presented in a vertical setup in the second, and vice versa. In Pachur et al. (2018), the acquisition mode in MouselabWEB was mouseover; in the second experiment, it was click.

Table A1 in the Appendix A presents the 91 choice problems used in both experiments, with 25 loss problems, 35 gain problems, and 31 mixed problems (i.e., including possible gains and losses). The numbers of loss and gain problems differ because the original set of problems in Pachur et al. (2018) was compiled from several sources. Importantly, the loss and gain outcomes were of similar magnitudes. The mean expected value of the gambles (both risky and safe) was -52.5 in the loss domain and 48.8 in the gain domain. ${ }^{5}$ For more details about the experimental setup, see Pachur et al. (2018).

\section{Results}

\subsection{Do losses prompt more attention than gains?}

We addressed this question by examining the amount of time that participants kept the individual boxes open while making decisions in problems in the loss domain versus the gain domain. We first computed the average opening time for each participant across problems, and then computed the average across participants for each domain. Fig. 2 shows the mean opening times in milliseconds across participants. ${ }^{6}$

Fig. 2 distinguishes between outcome and probability boxes. The pattern is clear: At the aggregate level, losses prompted markedly longer opening times than gains. This regularity occurred for both outcome and probability boxes. Moreover, it held across the first and second experimental sessions, as well as across the mouse and click

\footnotetext{
${ }^{5}$ To bring the mean expected value of the gain and loss gambles even closer together, we re-ran the analysis excluding the five problems in the gain domain whose mean expected value was lowest (i.e., problems 7, 14, 82, 83, and 84). When these problems were excluded, the mean expected value of the gambles in the gain domain was 52.7, almost identical to that in the loss domain. As shown in Fig. A2 (Appendix A), the resulting pattern was practically the same as that reported here for the full set of problems.

${ }^{6}$ In addition to using the mean of each participant's opening times across problems, all the analyses were conducted using the median, and results remain constant. We used the mean because we observed minor but systematic differences in the distributions across domains.
} 


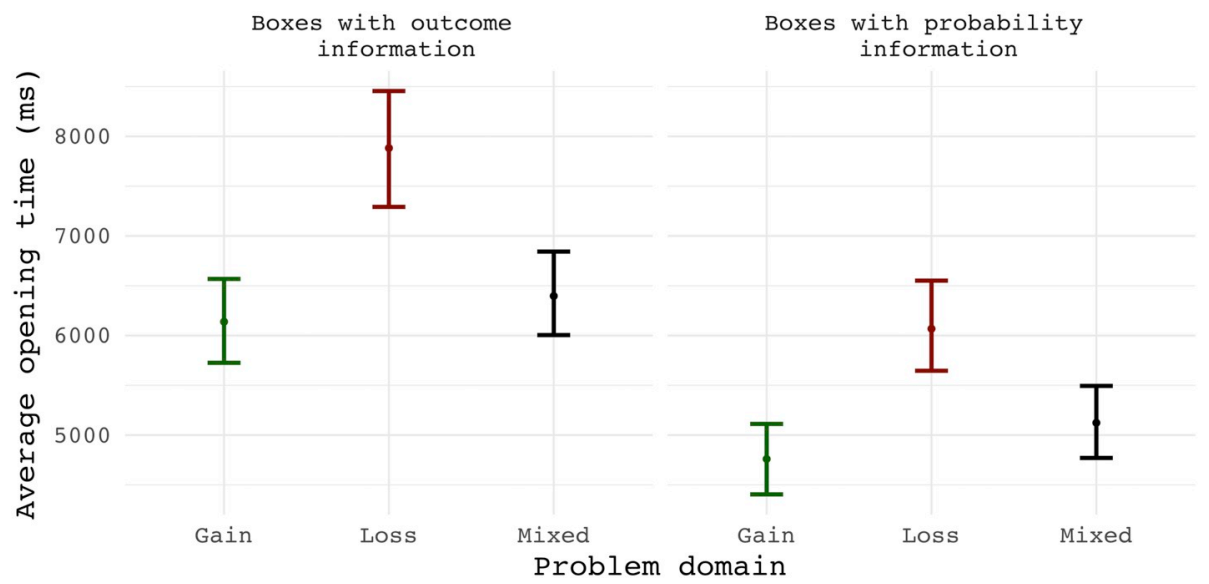

Fig. 2. Opening time (in milliseconds, averaged first across problems and then across participants) for boxes with outcome and probability information. The error bars represent bootstrapped $95 \%$ confidence intervals.

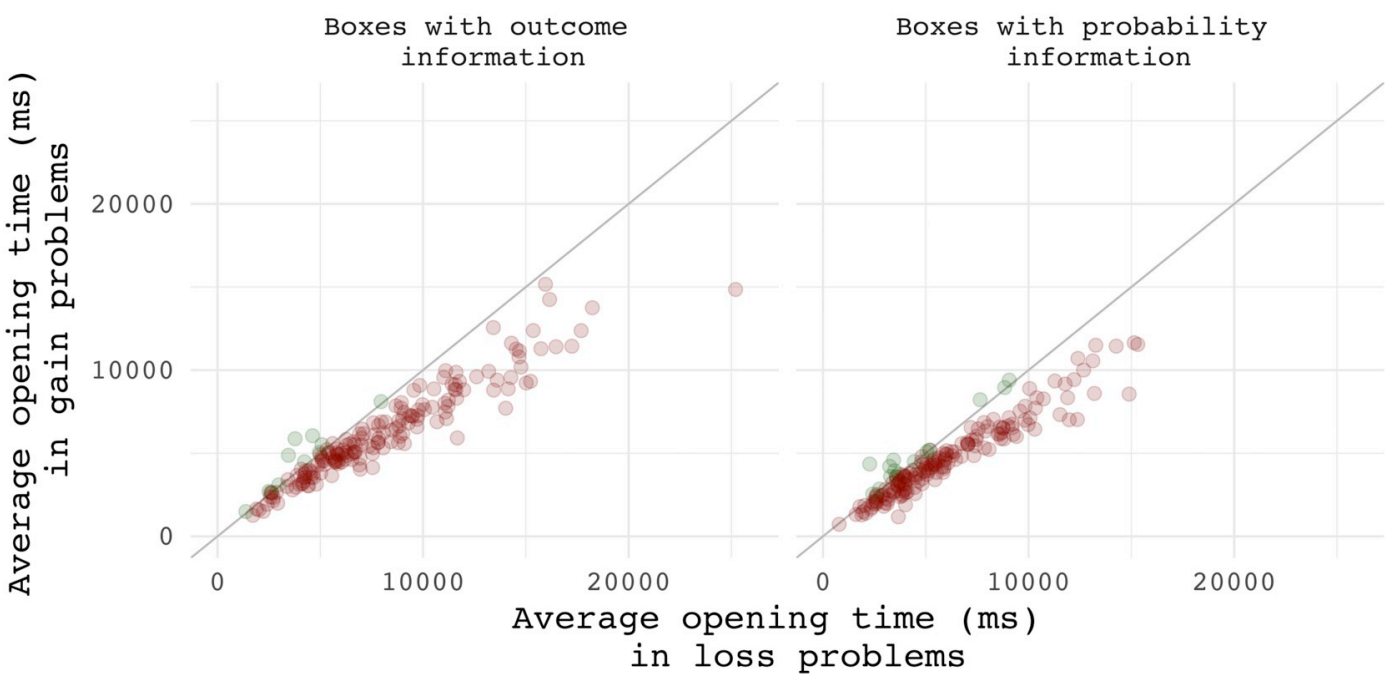

Fig. 3. Average opening time (in milliseconds) for gain and loss boxes in the loss and gain domains separately. Red dots represent participants who spent more time on losses than gains; green dots represent participants with the opposite pattern. (For interpretation of the references to colour in this figure legend, the reader is referred to the web version of this article.)

acquisition modes (see Appendix A). The average opening time for problems in the mixed domain fell between that of problems in the loss and gain domains. In principle, relative attention to losses and gains can also be examined within mixed gambles (which include a possible loss and a possible gain). However, because in these gambles the probabilities of both outcomes add up to 1 , participants can infer the complementary probability without needing to open the other probability box. We therefore restricted subsequent analyses to the gain and loss domains. Choices in the mixed domain are, however, included in the estimation of the individual degree of loss aversion.

One of the benefits of the present dataset is that it also allows us to examine attention to gains and losses at the individual level. Fig. 3 shows the opening time within each participant, comparing problems in the loss and gain domains. Each point represents a participant, and its coordinates in the scatterplot indicate the relative opening time of boxes in loss (x-axis) and gain (y-axis) problems. Points below the diagonal indicate longer opening times in the loss than in the gain domain. As can be seen, losses prompted longer inspection than gains at the individual level as well. When checking outcome information, 165 (94\%) participants opened loss boxes for longer than gain boxes; 11 (6\%) showed the opposite pattern. Likewise for probability information, 161 (91\%) participants opened loss probability boxes for longer than gain probability boxes; 15 (9\%) participants showed the opposite pattern.

In summary, at both the aggregate and the individual level, we observed longer box opening times for problems in the loss domain than 
for problems in the gain domain. This asymmetric pattern emerged for both outcomes and probabilities.

\subsection{Does loss aversion in choice depend on asymmetric attention to losses?}

To address this question, we first examined whether each individual participant exhibited loss aversion in their choices. The degree of loss aversion in choice is captured by prospect theory's loss aversion parameter, $\lambda$. Loss aversion is exhibited when $\lambda>1$, loss neutrality when $\lambda=1$, and gain seeking when $\lambda<1$. We estimated prospect theory parameters, including $\lambda$, for each participant using the hierarchical Bayesian approach as in Pachur et al. (2018). We estimated the parameters for each participant twice: once for each of the sessions. We then obtained the mean of the posterior distribution of $\lambda$ for each participant in the two sessions, and computed the mean between the two estimates. Thus, the mean of the $\lambda$ estimates is a measure of participants' loss aversion in choice. Four participants skipped more than $10 \%$ of the choice problems and were excluded from the analysis. As in Pachur et al. (2018), we used the ratio of box opening times in loss problems to gain problems as a measure of relative attention to losses, with values above 1 indicating loss attention. ${ }^{7}$ Our approach is similar to that reported in Pachur et al. (2018), with the exception that they examined relative attention within mixed gambles, whereas we compared attention in the loss and gain domains. There are two reasons for our methodological choice. First, as suggested by Yechiam and Hochman (2013b), the possibility of incurring a loss increases attention to all elements in a task. Therefore, using mixed gambles could conceal an asymmetry in the attention devoted to losses and gains, because attention to both outcomes will be increased. Second, because the two probabilities in mixed gambles must add up to 1 , the complementary probability can be inferred from one probability box without opening the other, thus complicating the measurement of attention to the loss and gain elements of a problem. Comparing attention across the gain and loss domains avoids these two issues. Fig. 4 shows the relationship between loss aversion, as estimated from choice, and asymmetry in attention (including both outcome and probability boxes).

The results show that, on the aggregate, there was practically no loss aversion in choice, as the mean $\lambda$ was 0.95 , 95\%CI $(0.93,0.98)$. These findings are consistent with the results of the review by Yechiam and Hochman (2013b), and other studies using a similarly comprehensive set of choice problems (Glöckner \& Pachur, 2012; Pachur et al., 2017; Rieskamp, 2008). In fact, only $40 \%$ of participants showed some degree of loss aversion (i.e., $\lambda>1$ ); the majority $(60 \%)$ showed the opposite, gain seeking (i.e., $\lambda<1$ ). As Fig. 4 reveals, an asymmetry in attention was present when people's choices were loss averse but, importantly, also when choices were loss neutral or gain seeking. Specifically, the figure shows a weak relationship between box opening time and loss aversion in choice: 166 participants (94\%) spent more time viewing losses than gains, but only $71(40 \%)$ were loss averse in their choices. In general, the asymmetry in attention was more prevalent than the asymmetry in choices: Most people were more attentive to losses, whereas only a minority were averse to them in their choices. Moreover, participants who exhibited loss-averse choices also largely showed the expected asymmetry in attention. Indeed, only two of the 71 loss-averse participants showed the opposite asymmetry in attention. Finally, of the 105 participants who were not loss averse, 97 were more attentive to losses than to gains (92\%).

These results suggest that loss attention is a necessary but not sufficient condition for loss aversion to emerge in choice. Fig. 4 shows that only a small proportion of participants exhibited loss aversion without loss attention (the upper-left quadrant); when this was the case, the

\footnotetext{
${ }^{7}$ Similar results emerged when we used the difference, rather than the ratio, between opening times in loss problems and gain problems as the measure of attention.
}

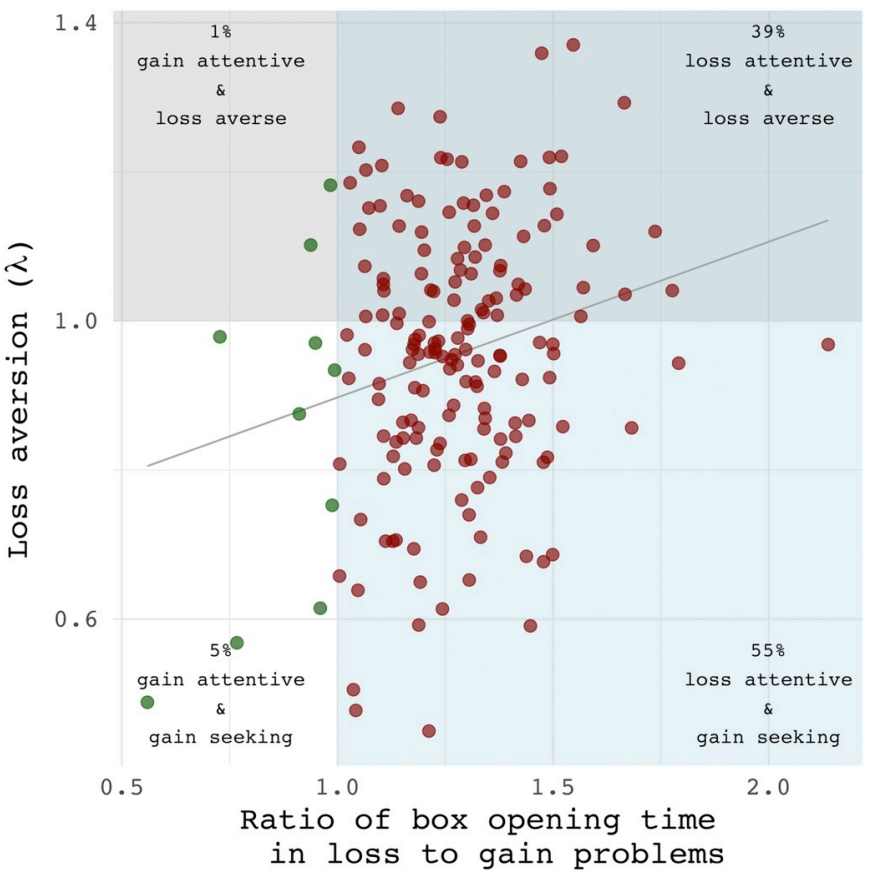

Fig. 4. Loss aversion as a function of attention to loss vs. gain information (i.e., including both outcome and probability boxes). Each dot represents a participant's loss aversion parameter $\lambda$ relative to the ratio of box opening times in loss problems to gain problems. The gray area indicates participants who were loss averse in their choices; the light blue area, participants who were loss attentive. The union of the two colors in the upper-right quadrant indicates participants who were both loss averse and loss attentive. (For interpretation of the references to colour in this figure legend, the reader is referred to the web version of this article.)

asymmetry in attention was minimal. Note that this conclusion-that is, that loss attention is a necessary condition for loss aversion-does not exclude the possibility that the $\lambda s$ and attention are related. Indeed, Pachur et al. (2018) examined how the $\lambda$ s correlated with the ratio of time allocated to losses relative to gains in mixed gambles. The results showed a moderate but robust correlation $\left(r_{s}=.31, p=.002\right.$, Spearman rank correlation). In their analysis, participants who were more loss averse also paid more attention to loss than to gain outcomes within mixed gambles. Pachur et al. also manipulated how much attention participants paid to gains and losses and observed a causal connection between the $\lambda s$ and attention. Focusing instead on gambles involving only gains or only losses, we also found a robust relationship, albeit a weaker one. The correlation between the $\lambda s$ and opening time was $r_{s}=.16, p=.04$, corroborating the pattern observed by Pachur et al. (2018).

\section{Discussion}

The evidence for loss aversion has recently been questioned. Using the standard experimental paradigm for the study of risky choice, we observed a robust pattern of increased attention to losses relative to gains, even though the large majority of participants showed no loss aversion in their choices.

The consistency of results across various neurophysiological and cognitive measures suggests that organisms devote more attention to losses than to gains of equivalent magnitude. Loss attention seems a common regularity in cognition, but it does not seem to determine choice. One way to think about the relationship of loss attention and loss aversion is in terms of loss aversion, in contrast to loss attention, being state-dependent.

McDermott et al. (2008) explored the potential evolutionary origins 


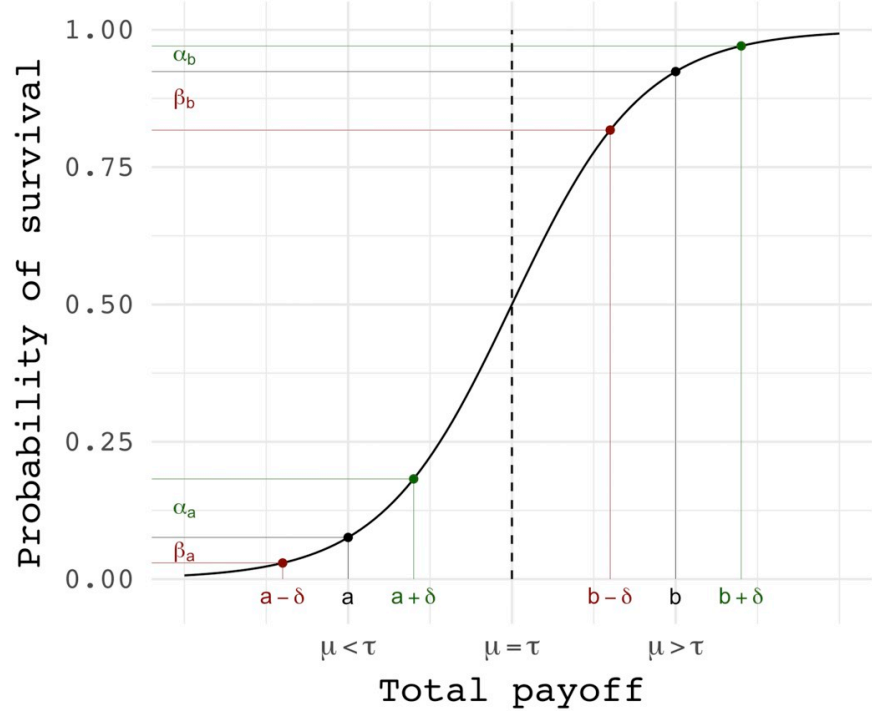

Fig. 5. Probability of survival according to McDermott et al. (2008). The expected payoff (e.g., energy) of an action is denoted by $\mu$. The survival threshold is $\tau$. The probability of survival is convex when $\mu<\tau$ and concave when $\mu>\tau$. At $a$, a gain of $\delta$ has a larger impact on the probability of survival than a loss of the same magnitude, $\alpha_{a}>\beta_{a}$. However, at $b$, a gain of $\delta$ has a smaller impact on the probability of survival than a loss of the same magnitude, $\alpha_{a}<\beta_{a}$, indicating loss aversion when the organism is sated.

of prospect theory preferences within the framework of risk-sensitivity theory, and proposed a survival function that captures some of the phenomena modeled by prospect theory. In their model, an organism has to achieve a minimum level of energy $\tau$ by the end of the day in order to survive the night. Fig. 5 illustrates the function that maps the organism's probability of survival as a function of the expected payoff $\mu$ (e.g., energy) and its distance to the survival threshold. The authors proposed that when the organism is in a state of need (i.e., below $\tau$ ), it will make decisions that also accept potential losses; when sated, it will make decisions that avoid the risk of losses. This function implies riskseeking preferences when in need, and risk aversion when sated. However, the authors do not address how this function might leads to a general aversion of losses-a notion they proposed under the ubiquitous condition of uncertain survival:

Outside the realms of reproduction and eating, few positive experiences offer fitness advantage. After all, in the end, there are natural limits on reproduction and raising offspring, which are higher for women than men, since the length of pregnancy places limits on the number of children a woman can bear. But surviving or avoiding even a single negative experience resulting from encounters with predators or poisoned food may prove essential for survival and fitness. In other words, when survival is uncertain, marginal losses prove more critical for reproductive success than marginal gains. (p. 337)

Although much of this is plausible, we agree with Houston et al. (2014) that McDermott et al. (2008)'s survival function does not reflect general loss aversion. Instead, we argue that such a function might reflect state-dependent loss aversion (Hertwig \& Lejarraga, 2019). Specifically, instead of considering all states above $\tau$ as gains and all states below $\tau$ as losses, let us adopt the assumption from prospect theory that it is changes in state that matter-in other words, that increases in wealth (or energy) are evaluated as gains, and that decreases are evaluated as losses. If an organism is in a state of need, say at point $a$, a gain of $\delta$ energy translates into an $\alpha_{a}$ increase in the probability of survival, and a loss of energy of the same magnitude $\delta$ translates into a $\beta_{a}$ decrease in the probability of survival. Given that $\alpha_{a}>\beta_{a}$, due to the convexity of the survival function when $\mu<\tau$, this organism in need will not be loss averse. In fact, this organism must risk a loss in order to stand a chance of surpassing the critical level $\tau$. In contrast, when this organism is above $\tau$, say at point $b$, the opposite holds. When the organism is sated, "losses loom larger than gains," $\beta_{b}>\alpha_{b}$. Now it will avoid the risk of a loss that might threaten its survival.

Mallpress et al. (2015) also view preferences as state-dependent. They simulated risky decision making in an evolutionary model, where organisms evolve patterns of behavior that allow them to gain and store energy and improve their reproductive fitness. Organisms within the constraints of this model may or may not reflect the patterns predicted by prospect theory, but Mallpress et al. (2015) indeed found that, under certain conditions, the patterns of behavior predicted by prospect theory evolved. In particular, they observed that behaving in line with prospect theory could be adaptive in environments where stochastic options are autocorrelated in time. Their simulation provides evidence that loss-averse choices are not a general tendency of organisms' behavior, but depend on environmental conditions.

Kahneman and Tversky (1979) also considered the possibility that people's circumstances might affect their preferences, and in particular loss aversion:

Any discussion of the utility function for money must leave room for the effect of special circumstances on preferences. For example, ... an individual's aversion to losses may increase sharply near the loss that would compel him to sell his house and move to a less desirable neighborhood. Hence, the derived value (utility) function of an individual does not always reflect "pure" attitudes to money, since it could be affected by additional consequences associated with specific amounts. (pp. 278-279)

For Kahneman and Tversky (1979), however, unlike Mallpress et al. (2015), context does not seem the main thrust of risk preferences but merely a special case.

To conclude, let us return to the question of how to conceptualize loss aversion. We suggest that the pattern of empirical findings presented here and elsewhere cannot be captured by conceptualizing loss aversion either in terms of a revealed-preference approach strictly restricted to choice, or as a latent psychological construct in which loss aversion in choice is synchronized with other preceding and accompanying processes. Instead, we propose that organisms may be generally attentive toward losses because the next loss can be deadly in an uncertain environment; there is no equivalent critical threshold in the domain of gains. Thus, organisms must devote resources to detecting losses. Being attentive to losses does not necessarily result in loss-averse choices, however. Loss aversion in choice, we suggest, could depend on the organism's state, as assumed by risk-sensitivity theory. In states of metabolic need, organisms must be ready to expose themselves to greater (and possibly even deadly) risks in order to meet and exceed an existential minimum threshold. But once the organism's need state is above this threshold, it will avoid potential losses that may jeopardize its survival. This view of loss aversion may help to explain the disconnect between many researchers' entrenched beliefs in the 
fundamental role of loss aversion and its empirical fragility. This disconnect may have emerged because a state-dependent aversion to losses in choice behavior has been confounded with a more context-invariant predisposition to screen one's environment for the threat of losses. An attention-aversion gap, in which loss attention reflects a general vigilance to the threat of a loss in the environment and represents a necessary but not a sufficient condition for loss aversion in behavior is, we suggest, the most promising way to explain the mounting evidence that loss aversion may not be as fundamental and even hard-wired a behavior as it seemed.

\section{Acknowledgements}

We thank David Pietraszewski and Jan K. Woike for helpful discussions and Susannah Goss for editing the manuscript.

\section{Appendix A. Appendix}

\section{A.1. Prospect theory}

Prospect theory (Kahneman \& Tversky, 1979), and its modified version cumulative prospect theory (Tversky \& Kahneman, 1992), is a descriptive theory of how people make choices between gambles or prospects. It proposes that people choose the gamble with the highest value. The value $V$ of a gamble $A$ with outcomes $x_{m}>\ldots>x_{1} \geq 0>y_{1}>\ldots>y_{n}$ and corresponding probabilities $p_{m} \ldots p_{1}$ and $q_{1} \ldots q_{n}$ is

$V(A)=\sum_{i=1}^{m} v\left(x_{i}\right) \pi_{i}^{+}+\sum_{j=1}^{n} v\left(y_{i}\right) \pi_{j}^{-}$

where $\pi$ is a weighting function of the outcome probabilities and $v$ is a function of outcomes satisfying

$v(0)=0$

$v(x)=x^{\alpha}$

$v(y)=-\lambda(-y)^{\alpha}$

where $\alpha(\geq 0)$ affects the curvature of $v . \lambda(\geq 0)$ specifies the degree of loss aversion, with larger values indicating higher degrees.

Decision weights are a function of the probabilities of the outcomes, and are transformed according to the rank of the outcomes in each domain. Specifically, the weights are

$$
\begin{gathered}
\pi_{m}^{+}=w^{+}\left(p_{m}\right) \\
\pi_{n}^{-}=w^{-}\left(p_{n}\right) \\
\pi_{i}^{+}=w^{+}\left(p_{i}+\ldots+p_{m}\right)-w^{+}\left(p_{i+1}+\ldots+p_{m}\right) \quad \text { for } \quad 1 \leq i<m \\
\pi_{j}^{-}=w^{-}\left(q_{j}+\ldots+q_{n}\right)-w^{-}\left(q_{j+1}+\ldots+q_{n}\right) \quad \text { for } \quad 1 \leq j<n
\end{gathered}
$$

where $w^{+}$and $w^{-}$are the probability-weighting functions for gains and losses, respectively, of the form

$$
\begin{aligned}
& w^{+}=\frac{\delta^{+} p^{\gamma^{+}}}{\delta^{+} p^{\gamma^{+}}+(1-p)^{\gamma^{+}}} \text {for } x \\
& w^{-}=\frac{\delta^{+} q^{\gamma^{-}}}{\delta^{-} q^{\gamma^{-}}+(1-q)^{\gamma^{-}}} \text {for } y
\end{aligned}
$$

where $\gamma^{+}$and $\gamma^{-}$(both $\geq 0$ ) determine the curvature of the weighting function in the gain and loss domains, respectively (in our estimation, we set $\gamma+=\gamma-$; cf. Pachur \& Kellen, 2013); and $\delta^{+}$and $\delta^{-}$(both $\geq 0$ ) determine the elevation of the weighting function for gains and losses, respectively (Goldstein \& Einhorn, 1987).

Finally, the probability of choosing option A over option B is given by the logistic rule

$p(A, B)=\frac{1}{1+e^{-\theta[V(A)-V(B)]}}$

with sensitivity parameter $\theta(\geq 0)$, with larger values of $\theta$ indicating more deterministic choices.

We estimated individual parameters for each participant, separately for each of the two sessions. We used the same hierarchical Bayesian approach and computer code as Pachur et al. (2018). We first defined prior distributions for parameter estimates, which were then updated into posterior distributions based on the observed choices. Because the hierarchical estimation partially pools individual estimates through group-level distributions, it has been found to yield more reliable estimates than the nonhierarchical approach (Nilsson, Rieskamp, \& Wagenmakers, 2011). We allowed parameters to vary in the range of 0 to 5 for $\theta, \lambda, \delta^{+}$and $\delta^{-}$, and in the range of 0 to 2 for $\alpha$ and $\gamma$. Further technical details about the estimation procedure are available in Pachur et al. (2018).

\section{A.2. Analysis of box time openings}

Fig. A1 shows that the loss-gain asymmetry in box openings was consistent across outcomes and probabilities, session 1 and session 2 , and click and mouseover acquisition modes. 

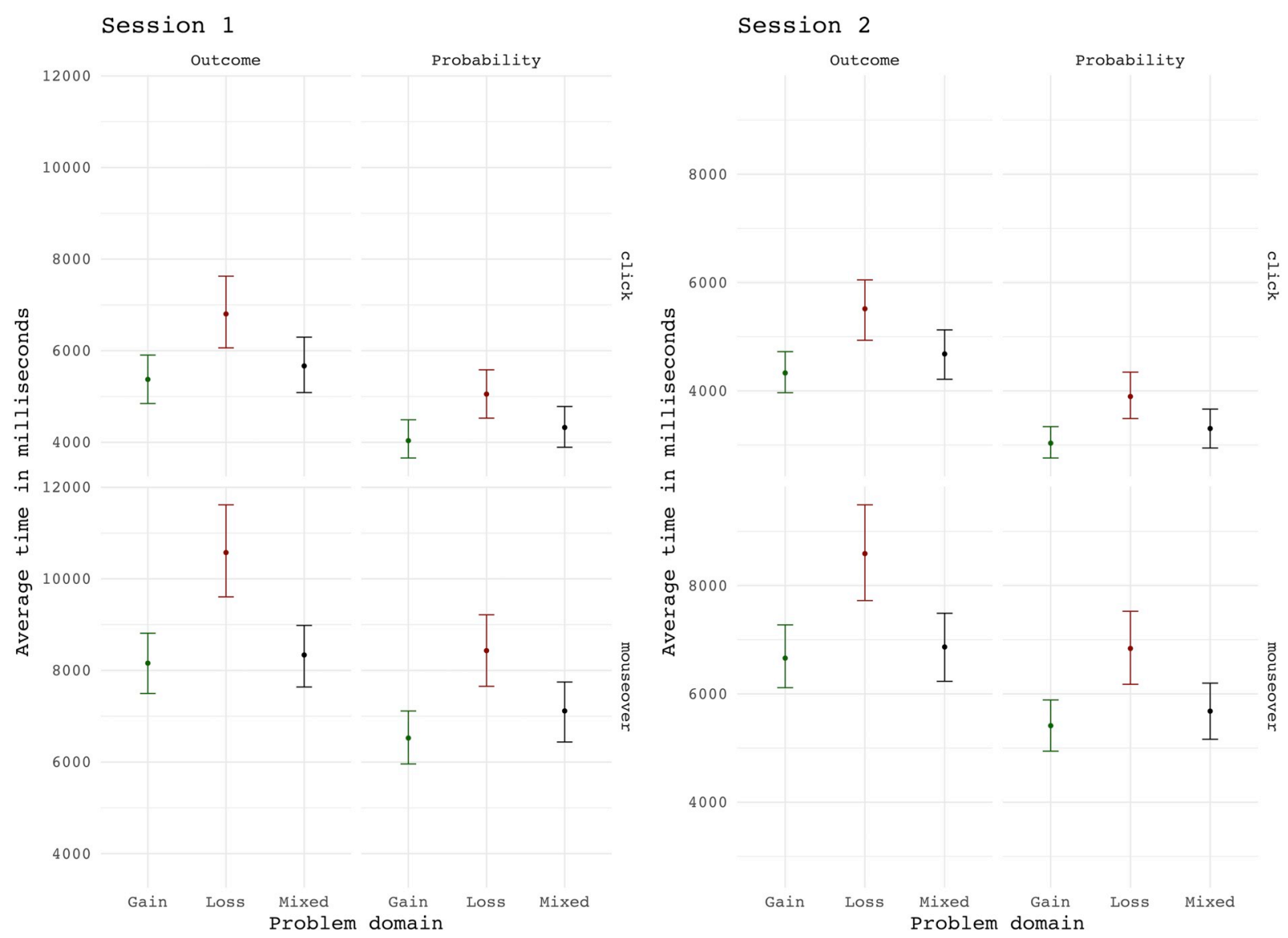

Fig. A1. Average opening time (in milliseconds) for boxes with outcome and probability information. The error bars represent bootstrapped $95 \%$ confidence intervals. The averages are broken down by problem domain (loss, gain, and mixed), by experimental session (sessions 1 and 2 ), and by acquisition mode (click and mouseover).

A.3. Re-analysis of box time openings, with five problems being excluded to achieve equivalence of expected values in the loss and gain domains

Fig. A2 shows the same analysis as in Fig. A1, now excluding the five problems in the gain domain with the lowest expected values (i.e., problems $7,14,82,83$, and 84$)$. When these problems were excluded, the mean expected value in the gain domain was 52.7, almost equivalent to that in the loss domain $(-52.5)$. 

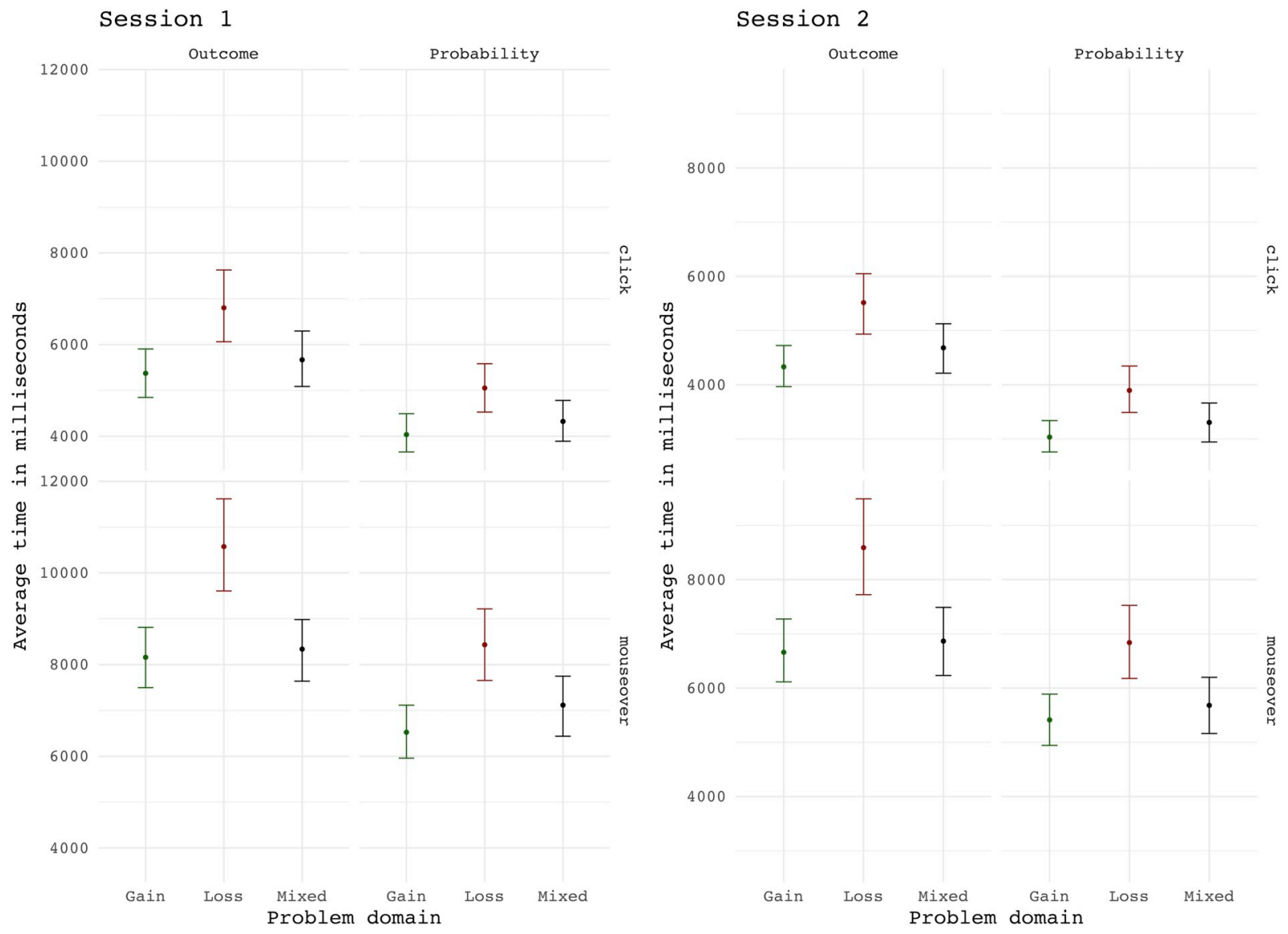

Fig. A2. Average opening time (in milliseconds) for boxes with outcome and probability information. The error bars represent bootstrapped $95 \%$ confidence intervals. The averages are broken down by problem domain (loss, gain, and mixed), by experimental session (sessions 1 and 2), and by acquisition mode (click and mouseover). This analysis excludes gain problems $7,14,82,83$, and 84 .

\section{A.4. The 91 decision problems included in the analysis}

Table A1

Overview of the 91 decision problems used in the experiments. Column oA1 shows one outcome of option A; pA1, its probability. Column oA2 shows the other outcome of option A; pA2, its probability (i.e., 1 - pA1). The same logic applies to the columns for option B.

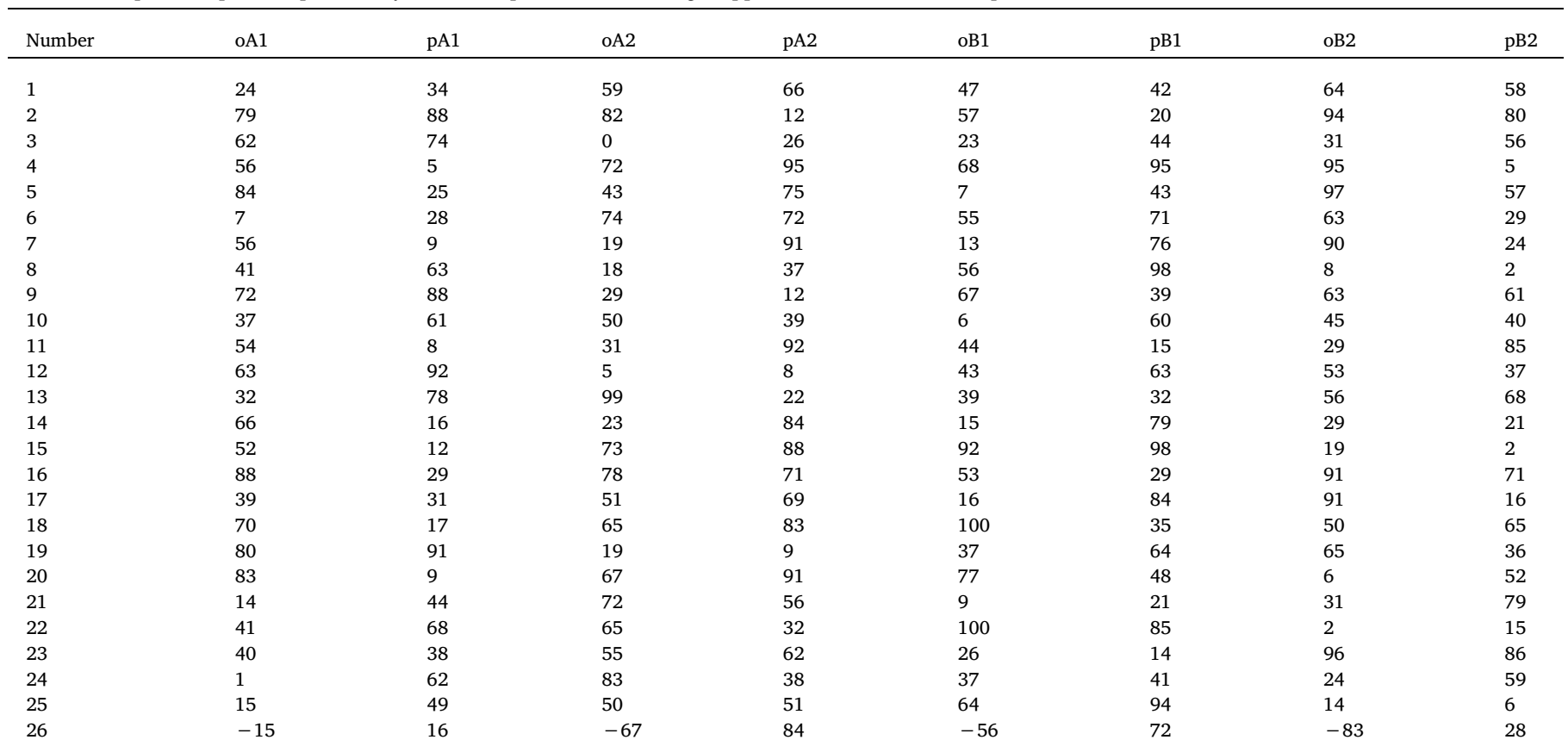

(continued on next page) 
Table A1 (continued)

\begin{tabular}{|c|c|c|c|c|c|c|c|c|}
\hline Number & oA1 & pA1 & oA2 & pA2 & oB1 & $\mathrm{pB} 1$ & oB2 & $\mathrm{pB} 2$ \\
\hline 27 & -19 & 13 & -56 & 87 & -32 & 70 & -37 & 30 \\
\hline 28 & -67 & 29 & -28 & 71 & -46 & 5 & -44 & 95 \\
\hline 29 & -40 & 82 & -90 & 18 & -46 & 17 & -64 & 83 \\
\hline 30 & -25 & 29 & -86 & 71 & -38 & 76 & -99 & 24 \\
\hline 31 & -46 & 60 & -21 & 40 & -99 & 42 & -37 & 58 \\
\hline 32 & -15 & 48 & -91 & 52 & -48 & 28 & -74 & 72 \\
\hline 33 & -93 & 53 & -26 & 47 & -52 & 80 & -93 & 20 \\
\hline 34 & -1 & 49 & -54 & 51 & -33 & 77 & -30 & 23 \\
\hline 35 & -24 & 99 & -13 & 1 & -15 & 44 & -62 & 56 \\
\hline 36 & -67 & 79 & -37 & 21 & 0 & 46 & -97 & 54 \\
\hline 37 & -58 & 56 & -80 & 44 & -58 & 86 & -97 & 14 \\
\hline 38 & -96 & 63 & -38 & 37 & -12 & 17 & -69 & 83 \\
\hline 39 & -55 & 59 & -77 & 41 & -30 & 47 & -61 & 53 \\
\hline 40 & -29 & 13 & -76 & 87 & -100 & 55 & -28 & 45 \\
\hline 41 & -57 & 84 & -90 & 16 & -63 & 25 & -30 & 75 \\
\hline 42 & -29 & 86 & -30 & 14 & -17 & 26 & -43 & 74 \\
\hline 43 & -8 & 66 & -95 & 34 & -42 & 93 & -30 & 7 \\
\hline 44 & -35 & 39 & -72 & 61 & -57 & 76 & -28 & 24 \\
\hline 45 & -26 & 51 & -76 & 49 & -48 & 77 & -34 & 23 \\
\hline 46 & -73 & 73 & -54 & 27 & -42 & 17 & -70 & 83 \\
\hline 47 & -66 & 49 & -92 & 51 & -97 & 78 & -34 & 22 \\
\hline 48 & -9 & 56 & -56 & 44 & -15 & 64 & -80 & 36 \\
\hline 49 & -61 & 96 & -56 & 4 & -7 & 34 & -63 & 66 \\
\hline 50 & -4 & 56 & -80 & 44 & -46 & 4 & -58 & 96 \\
\hline 51 & -91 & 43 & 63 & 57 & -83 & 27 & 24 & 73 \\
\hline 52 & -82 & 6 & 54 & 94 & 38 & 91 & -73 & 9 \\
\hline 53 & -70 & 79 & 98 & 21 & -85 & 65 & 93 & 35 \\
\hline 54 & -8 & 37 & 52 & 63 & 23 & 87 & -39 & 13 \\
\hline 55 & 96 & 61 & -67 & 39 & 71 & 50 & -26 & 50 \\
\hline 56 & -47 & 43 & 63 & 57 & -69 & 2 & 14 & 98 \\
\hline 57 & -70 & 39 & 19 & 61 & 8 & 30 & -37 & 70 \\
\hline 58 & -100 & 59 & 81 & 41 & -73 & 47 & 15 & 53 \\
\hline 59 & -73 & 92 & 96 & 8 & 16 & 11 & -48 & 89 \\
\hline 60 & -31 & 89 & 27 & 11 & 26 & 36 & -48 & 64 \\
\hline 61 & -39 & 86 & 83 & 14 & 8 & 80 & -88 & 20 \\
\hline 62 & 77 & 74 & -23 & 26 & 75 & 67 & -7 & 33 \\
\hline 63 & -33 & 91 & 28 & 9 & 9 & 27 & -67 & 73 \\
\hline 64 & 75 & 93 & -90 & 7 & 96 & 87 & -89 & 13 \\
\hline 65 & 67 & 99 & -3 & 1 & 74 & 68 & -2 & 32 \\
\hline 66 & 58 & 48 & -5 & 52 & -40 & 40 & 96 & 60 \\
\hline 67 & -55 & 7 & 95 & 93 & -13 & 48 & 99 & 52 \\
\hline 68 & -51 & 97 & 30 & 3 & -89 & 68 & 46 & 32 \\
\hline 69 & -26 & 86 & 82 & 14 & -39 & 60 & 31 & 40 \\
\hline 70 & -90 & 88 & 88 & 12 & -86 & 80 & 14 & 20 \\
\hline 71 & -78 & 87 & 45 & 13 & -69 & 88 & 83 & 12 \\
\hline 72 & 17 & 96 & -48 & 4 & -60 & 49 & 84 & 51 \\
\hline 73 & -49 & 38 & 2 & 62 & 19 & 22 & -18 & 78 \\
\hline 74 & -59 & 28 & 96 & 72 & -4 & 4 & 63 & 96 \\
\hline 75 & 98 & 50 & -24 & 50 & -76 & 14 & 46 & 86 \\
\hline 76 & -20 & 50 & 60 & 50 & 0 & 50 & 0 & 50 \\
\hline 77 & -30 & 50 & 60 & 50 & 0 & 50 & 0 & 50 \\
\hline 78 & -40 & 50 & 60 & 50 & 0 & 50 & 0 & 50 \\
\hline 79 & -50 & 50 & 60 & 50 & 0 & 50 & 0 & 50 \\
\hline 80 & -60 & 50 & 60 & 50 & 0 & 50 & 0 & 50 \\
\hline 81 & -70 & 50 & 60 & 50 & 0 & 50 & 0 & 50 \\
\hline 82 & 40 & 10 & 32 & 90 & 77 & 10 & 2 & 90 \\
\hline 83 & 40 & 20 & 32 & 80 & 77 & 20 & 2 & 80 \\
\hline 84 & 40 & 30 & 32 & 70 & 77 & 30 & 2 & 70 \\
\hline 85 & 40 & 40 & 32 & 60 & 77 & 40 & 2 & 60 \\
\hline 86 & 40 & 50 & 32 & 50 & 77 & 50 & 2 & 50 \\
\hline 87 & 40 & 60 & 32 & 40 & 77 & 60 & 2 & 40 \\
\hline 88 & 40 & 70 & 32 & 30 & 77 & 70 & 2 & 30 \\
\hline 89 & 40 & 80 & 32 & 20 & 77 & 80 & 2 & 20 \\
\hline 90 & 40 & 90 & 32 & 10 & 77 & 90 & 2 & 10 \\
\hline 91 & 40 & 100 & 32 & 0 & 77 & 100 & 2 & 0 \\
\hline
\end{tabular}

\section{References}

Aktipis, C. A., \& Kurzban, R. O. (2005). Is homo economicus extinct? Vernon Smith, Daniel Kahneman and the evolutionary perspective. In R. Koppl (Ed.). Evolutionary psychology and economic theory (pp. 135-153). Bingley, UK: Emerald Group Publishing.

Ashby, N. J., Yechiam, E., \& Ben-Eliezer, D. (2018). The consistency of visual attention to losses and loss sensitivity across valuation and choice. Journal of Experimental Psychology: General, 147, 1791-1809.

Barclay, P., Mishra, S., \& Sparks, A. M. (2018). State-dependent risk-taking. Proceedings of the Royal Society B, 285, 20180180.

Baumeister, R. F., Bratslavsky, E., Finkenauer, C. \& Vohs, K. D. (2001). Bad is stronger than good. Review of General Psychology, 5, 323-370.

Benartzi, S., \& Thaler, R. H. (1995). Myopic loss aversion and the equity premium puzzle, The Quarterly Journal of Economics, 110, 73-92. 
Burke, C. J., Soutschek, A., Weber, S., Beharelle, A. R., Fehr, E., Haker, H., \& Tobler, P. N. (2018). Dopamine receptor-specific contributions to the computation of value. Neuropsychopharmacology, 43, 1415-1424.

Canessa, N., Crespi, C., Motterlini, M., Baud-Bovy, G., Chierchia, G., Pantaleo, G., ... Cappa, S. F. (2013). The functional and structural neural basis of individual differences in loss aversion. Journal of Neuroscience, 33, 14307-14317.

Edgeworth, F. Y. (1877). New and old methods of ethics: Or "physical ethics" and "methods of ethics" Oxford, UK: J. Parker.

Ert, E., \& Erev, I. (2013). On the descriptive value of loss aversion in decisions under risk: Six clarifications. Judgment and Decision Making, 8, 214-235.

Fishburn, P. C., \& Kochenberger, G. A. (1979). Two-piece von Neumann-Morgenstern utility functions. Decision Sciences, 10, 503-518.

Gal, D. (2006). A psychological law of inertia and the illusion of loss aversion. Judgment and Decision making, 1, 23-32.

Gal, D. (2018). Why the most important idea in behavioral decision-making is a fallacy. Retrieved from https://blogs.scientificamerican.com/observations/why-the-mostimportantidea-in-behavioral-decision-making-is-a-fallacy/.

Gal, D., \& Rucker, D. D. (2018a). Loss aversion, intellectual inertia, and a call for a more contrarian science: A reply to Simonson \& Kivetz and Higgins \& Liberman. Journal of Consumer Psychology, 28, 533-539.

Gal, D., \& Rucker, D. D. (2018b). The loss of loss aversion: Will it loom larger than its gain? Journal of Consumer Psychology, 28, 497-516.

Galanter, E., \& Pliner, P. (1974). Cross-modality matching of money against other continua. In H. R. Moskowitz, B. Scharf, \& J. C. Stevens (Eds.). Sensation and measurement (pp. 65-76). Dordrecht, the Netherlands.

Glöckner, A., \& Pachur, T. (2012). Cognitive models of risky choice: Parameter stability and predictive accuracy of prospect theory. Cognition, 123, 21-32.

Goldstein, W. M., \& Einhorn, H. J. (1987). Expression theory and the preference reversal phenomena. Psychological Review, 94, 236-254.

Haselton, M. G., \& Buss, D. M. (2000). Error management theory: A new perspective on biases in cross-sex mind reading. Journal of Personality and Social Psychology, 78, 81-91.

Hertwig, R., Barron, G., Weber, E. U., \& Erev, I. (2004). Decisions from experience and the effect of rare events in risky choice. Psychological Science, 15, 534-539.

Hertwig, R., \& Erev, I. (2009). The description-experience gap in risky choice. Trends in Cognitive Sciences, 13, 517-523.

Hertwig, R., \& Lejarraga, T. (2019). Loss aversion is risk aversion with a reference point: Views from prospect theory, utility theory, and risk-sensitivity theory. (Manuscript in preparation).

Hochman, G., \& Yechiam, E. (2011). Loss aversion in the eye and in the heart: The autonomic nervous system's responses to losses. Journal of Behavioral Decision Making 24, 140-156.

Houston, A. I., Fawcett, T. W., Mallpress, D. E., \& McNamara, J. M. (2014). Clarifying the relationship between prospect theory and risk-sensitive foraging theory. Evolution and Human Behavior, 35, 502-507.

Johnson, D. D., Blumstein, D. T., Fowler, J. H., \& Haselton, M. G. (2013). The evolution of error: Error management, cognitive constraints, and adaptive decision-making biases. Trends in Ecology \& Evolution, 28, 474-481.

Kahneman, D., Knetsch, J. L., \& Thaler, R. H. (1990). Experimental tests of the endowment effect and the Coase theorem. Journal of Political Economy, 98, 1325-1348.

Kahneman, D., Knetsch, J. L., \& Thaler, R. H. (1991). Anomalies: The endowment effect, loss aversion, and status quo bias. Journal of Economic Perspectives, 5, 193-206.

Kahneman, D., \& Tversky, A. (1979). Prospect theory: An analysis of decision under risk. Econometrica, 47, 263-292.

Kellen, D., Pachur, T., \& Hertwig, R. (2016). How (in)variant are subjective representations of described and experienced risk and rewards? Cognition, 157, 126-138.

Lejarraga, T., \& Hertwig, R. (2017). How the threat of losses makes people explore more than the promise of gains. Psychonomic Bulletin \& Review, 24, 708-720.

Lejarraga, T., Hertwig, R., \& Gonzalez, C. (2012). How choice ecology influences search in decisions from experience. Cognition, 124, 334-342.

Mallpress, D. E., Fawcett, T. W., Houston, A. I., \& McNamara, J. M. (2015). Risk attitudes in a changing environment: An evolutionary model of the fourfold pattern of risk preferences. Psychological Review, 122, 364-375.

Margittai, Z., Nave, G., Van Wingerden, M., Schnitzler, A., Schwabe, L., \& Kalenscher, T. (2018). Combined effects of glucocorticoid and noradrenergic activity on loss aversion. Neuropsychopharmacology, 43, 334-341.

McDermott, R., Fowler, J. H., \& Smirnov, O. (2008). On the evolutionary origin of prospect theory preferences. The Journal of Politics, 70, 335-350.

Mishra, S., Barclay, P., \& Sparks, A. (2017). The relative state model: Integrating needbased and ability-based pathways to risk-taking. Personality and Social Psychology Review, 21, 176-198.

Mishra, S., Gregson, M., \& Lalumiere, M. L. (2012). Framing effects and risk-sensitive decision making. British Journal of Psychology, 103, 83-97.

Morewedge, C. K., Shu, L. L., Gilbert, D. T., \& Wilson, T. D. (2009). Bad riddance or good rubbish? Ownership and not loss aversion causes the endowment effect. Journal of Experimental Social Psychology, 45, 947-951.

Nilsson, H., Rieskamp, J., \& Wagenmakers, E.-J. (2011). Hierarchical Bayesian parameter estimation for cumulative prospect theory. Journal of Mathematical Psychology, 55, 84-93.

Novemsky, N., \& Kahneman, D. (2005). The boundaries of loss aversion. Journal of
Marketing Research, 42, 119-128.

Pachur, T., \& Kellen, D. (2013). Modeling gain-loss asymmetries in risky choice: The critical role of probability weighting. Cooperative minds: Social interaction and group dynamics. In Knauff. M, Pauen. M, Sebanz. N, \& Wachsmuth. I (Eds.). Proceedings of the 35th Annual Conference of the Cognitive Science Society (pp. 32053210). Austin, TX: Cognitive Science Society.

Pachur, T., \& Scheibehenne, B. (2017). Unpacking buyer-seller differences in valuation from experience: A cognitive modeling approach. Psychonomic Bulletin \& Review, 24, $1742-1773$.

Pachur, T., Mata, R., \& Hertwig, R. (2017). Who dares, who errs? Disentangling cognitive and motivational roots of age differences in decisions under risk. Psychological Science, 28, 504-518.

Pachur, T., Schulte-Mecklenbeck, M., Murphy, R. O., \& Hertwig, R. (2018). Prospect theory reflects selective allocation of attention. Journal of Experimental Psychology: General, 147, 147-169.

Payne, J. W., Bettman, J. R., \& Johnson, E. J. (1988). Adaptive strategy selection in decision making. Journal of Experimental Psychology: Learning, Memory, and Cognition, 14, 534-552.

Riedl, D., Heuer, A., \& Strauss, B. (2015). Why the three-point rule failed to sufficiently reduce the number of draws in soccer: An application of prospect theory. Journal of Sport and Exercise Psychology, 37, 316-326.

Rieskamp, J. (2008). The probabilistic nature of preferential choice. Journal of Experimental Psychology: Learning, Memory, and Cognition, 34, 1446-1465.

Ritov, I., \& Baron, J. (1992). Status-quo and omission biases. Journal of Risk and Uncertainty, 5, 49-61.

Rozin, P., \& Royzman, E. B. (2001). Negativity bias, negativity dominance, and contagion. Personality and Social Psychology Review, 5, 296-320.

Samuelson, P. A. (1938). A note on the pure theory of consumer's behaviour. Economica, 5, 61-71.

Samuelson, W., \& Zeckhauser, R. (1988). Status quo bias in decision making. Journal of Risk and Uncertainty, 1, 7-59.

Schulte-Mecklenbeck, M., Johnson, J. G., Böckenholt, U., Goldstein, D. G., Russo, J. E., Sullivan, N. J., \& Willemsen, M. C. (2017). Process-tracing methods in decision making: On growing up in the 70s. Current Directions in Psychological Science, 26, 442-450.

Schulte-Mecklenbeck, M., Pachur, T., Murphy, R., \& Hertwig, R. (2014). Does search determine choice? Paper presented at the 56th conference of experimental psychologists. Germany: Giessen.

Sokol-Hessner, P., Camerer, C. F., \& Phelps, E. A. (2012). Emotion regulation reduces loss aversion and decreases amygdala responses to losses. Social Cognitive and Affective Neuroscience, 8, 341-350.

Sokol-Hessner, P., Hsu, M., Curley, N. G., Delgado, M. R., Camerer, C. F., \& Phelps, E. A. (2009). Thinking like a trader selectively reduces individuals' loss aversion. Proceedings of the National Academy of Sciences, 106, 5035-5040.

Stephens, D. W. (1981). The logic of risk-sensitive foraging preferences. Animal Behaviour, 29, 628-629.

Stephens, D. W., \& Krebs, J. R. (1986). Foraging theory. Princeton, NJ: Princeton University Press.

Thaler, R. (1980). Toward a positive theory of consumer choice. Journal of Economic Behavior \& Organization, 1, 39-60.

Tom, S. M., Fox, C. R., Trepel, C., \& Poldrack, R. A. (2007). The neural basis of loss aversion in decision-making under risk. Science, 315, 515-518.

Tversky, A., \& Kahneman, D. (1991). Loss aversion in riskless choice: A reference-dependent model. The Quarterly Journal of Economics, 106, 1039-1061.

Tversky, A., \& Kahneman, D. (1992). Advances in prospect theory: Cumulative representation of uncertainty. Journal of Risk and Uncertainty, 5, 297-323.

Walasek, L., \& Stewart, N. (2015). How to make loss aversion disappear and reverse: Tests of the decision by sampling origin of loss aversion. Journal of Experimental Psychology: General, 144, 7-11.

Weber, M., \& Camerer, C. F. (1998). The disposition effect in securities trading: An experimental analysis. Journal of Economic Behavior \& Organization, 33, 167-184.

Willemsen, M. C., \& Johnson, E. J. (2019). (Re)visiting the decision factory: Observing cognition with MouselabWEB. In M. Schulte-Mecklenbeck, A. Kuhberger, \& J. Johnson (Eds.). A handbook of process tracing methods (pp. 73-92). New York, NY: Taylor \& Francis (p. TBD).

Yechiam, E. (2018). Acceptable losses: The debatable origins of loss aversion. Psychological Research, 1-13.

Yechiam, E., \& Hochman, G. (2013a). Loss-aversion or loss-attention: The impact of losses on cognitive performance. Cognitive Psychology, 66, 212-231.

Yechiam, E., \& Hochman, G. (2013b). Losses as modulators of attention: Review and analysis of the unique effects of losses over gains. Psychological Bulletin, 139, 497-518.

Yechiam, E., \& Hochman, G. (2014). Loss attention in a dual-task setting. Psychological Science, 25, 494-502.

Yechiam, E., Retzer, M., Telpaz, A., \& Hochman, G. (2015). Losses as ecological guides: Minor losses lead to maximization and not to avoidance. Cognition, 139, 10-17.

Yechiam, E., Zahavi, G., \& Arditi, E. (2015). Loss restlessness and gain calmness: Durable effects of losses and gains on choice switching. Psychonomic Bulletin \& Review, 22, 1096-1103. 